\title{
Successful valve replacement for aortic incompetence in rheumatoid arthritis with vasculitis
}

\author{
M. LIEW, D. WILSON, D. HORTON, AND A. FLEMING \\ From the Divisions of Rheumatology, Cardiology, and Cardiothoracic Surgery, Prince Henry Hospital, Sydney, \\ Australia
}

SUMMARY A patient with rheumatoid arthritis (RA), vasculitis, and aortic valve incompetence of the histologically nonspecific type is described. Valve replacement was undertaken, and an excellent haemodynamic result was achieved. Both arthritis and vasculitis subsequently remitted. Valve replacement can be successfully performed in RA despite active vasculitis.

Cardiac valvular disease in association with rheumatoid arthritis (RA) has been described for some time (Baggenstoss and Rosenberg, 1941, 1944). The aortic valve may be involved, either with granulomata (Iveson et al., 1975) or nonspecifically (Lebowitz, 1963). To date 10 cases of aortic valve replacement have been reported (Barker 1971; Iveson et al., 1975; Yates and Scott, 1975; Barraclough et al., 1975; Iveson and Pomerance, 1977). Only 1 of these had concommitant vasculitis, and this patient died after surgery (Yates and Scott, 1975). The last authors rightly emphasised the danger of surgery when systemic features are present. We report a case of successful aortic valve replacement for incompetence in a patient with RA and active vasculitis.

\section{Case report}

A 54-year-old man was admitted because of progressive symptoms of the left ventricular failure due to aortic incompetence. He had a 10-year history of seropositive, nodular, erosive RA. The onset of arthritis was peripheral and symmetrical and gradually involved almost all joints. The course had been remitting but progressive and destructive. The only treatment was with nonsteroidal anti-inflammatory analgesics. Three years prior to admission he developed crops of nail-fold vasculitic lesions without other systemic manifestations. Four days prior to admission he developed breathlessness to exertion and at rest, and these symptoms rapidly deteriorated. There was no history of rheumatic fever.

Physical examination revealed rheumatoid deformities with moderately active synovitis, nodules, and vasculitic lesions of hands and feet (Fig. 1). Blood pressure was $170 / 60 \mathrm{mmHg}$. Jugular venous pressure was raised $6 \mathrm{~cm}$. He had a collapsing pulse. The heart was enlarged. An early aortic diastolic murmur and an Austin-Flint murmur were heard. There were basal crepitations. Severe aortic incompetence was confirmed by echocardiography and cardiac catherisation. Other investigations showed $\mathrm{Hb} 13.9 \mathrm{~g} / \mathrm{dl}$, leucocytes $7.0 \times 10^{9} / 1$, ESR $52 \mathrm{~mm}$ in 1 hour, RoseWaaler titre $1: 256$, antinuclear antibody positive,

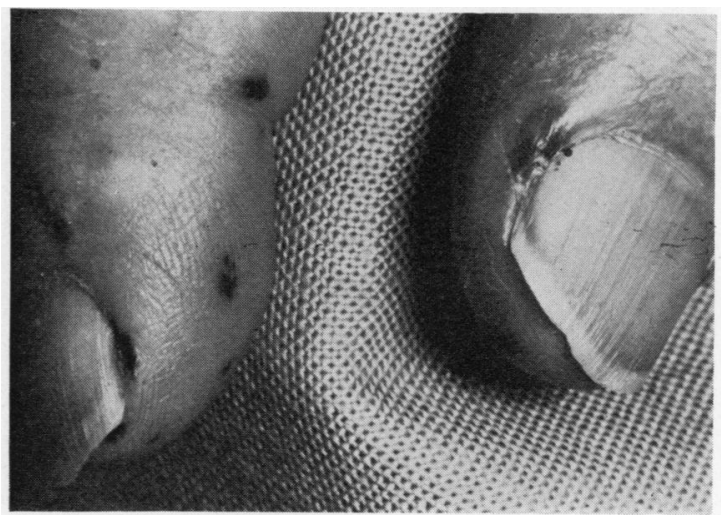

Fig. 1 Vasculitic lesions 
native DNA binding $2 \cdot 8 \%$ by Farr assay. A chest roentgenogram showed congestive changes. An electrocardiogram showed left ventricular hypertrophy. Multiple blood cultures failed to isolate a pathogen. His cardiac failure was unsatisfactorily controlled with an anticongestive regimen of digoxin $0.25 \mathrm{mg}$ and frusemide $80 \mathrm{mg}$ daily with potassium supplementation. Dyspnoea and physical signs of aortic regurgitation remained prominent. Aortic valve replacement was considered necessary and was performed 3 months after presentation.

At operation the valve leaflets were grossly thickened, shrunken, and retracted. There were no vegetations. Valve replacement by a Starr-Edwards prosthesis was successfully carried out. The valve histology showed fibrous thickening with foci of polymorphonuclear leucocytic, lymphocytic, and plasma cell infiltration (Fig. 2).

Postoperatively cardiac function has remained excellent. Sodium aurothiomalate (Myocrisin) was started just before surgery and in the subsequent 18 months follow-up period the patient has had a remission of his arthritis and the vasculitis has resolved.

\section{Discussion}

Valvular heart disease in RA is well recognised (Iveson et al., 1975). The aortic and mitral valves are most commonly effected (Roberts et al., 1968). The lesions appear clinically significant in about

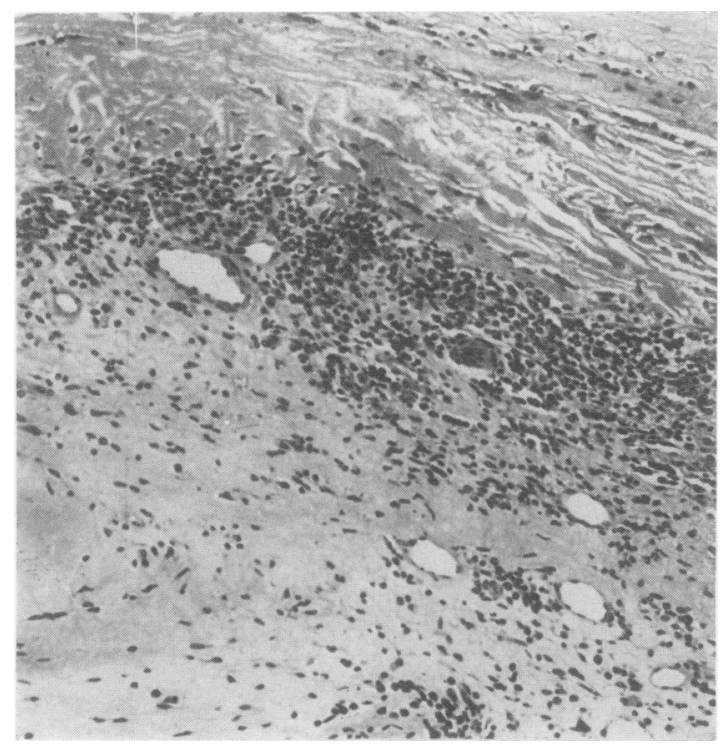

Fig. 2 Aortic valve leaflet showing mononuclear cell infiltration $(\times 175)$ one-third of cases. The commonest symptom detected is congestive cardiac failure (Sokoloff $\overrightarrow{\overrightarrow{2}}$ 1964). Of the 10 cases of aortic valve replacement reported granulomata were seen in 4 and a nonf specific valvulitis in 6 . Successful valve replacement was obtained in 9 of the 10 cases, and this mader possible the continuation of physical therapy for arthritis.

The danger of surgery for valvular disease when $\vec{p}$ systemic features accompany inflammatory dis $=$ orders of connective tissue was stressed by Yates and Scott (1975). Of the 3 cases they reported 2 died aftee operation as a result of systemic disease. One had systemic lupus erythematosus and nephritis and the other RA and vasculitis.

Our patient had a disease which was seropositive nodular, erosive, and active. There was obvious vasculitis at the time of surgery. There was no pas? history of rheumatic fever. The valvular changes wero consistent with histologically nonspecific type. The result of aortic valve replacement was excellento with return of normal exercise tolerance. Furthermore, with the subsequent continuation of goldo therapy good remission was obtained, and vasculitişo disappeared. Our case is the first illustration that, if there is severe aortic incompetence requiring replacement, surgery is worthwhile and technically feasible despite accompanying rheumatoid vasculitisg

\section{References}

Baggenstoss, A. H., and Rosenberg, E. F. (1941). Cardiac lesions associated with chronic infective arthritis. Archives of Internal Medicine, 67, 241-258.

Baggenstoss, A. H., and Rosenberg, E. F. (1944). UnusuaP. cardiac lesions associated with chronic multiple rheue matoid arthritis. Archives of Pathology, 37, 54-60.

Barker, A. (1971). Rheumatoid arthritis and rheumatoid heart disease. New Zealand Medical Journal, 73, 14-18

Barraclough, D. R. G., Muirden, K. D., and Hassall, J. E? (1975). Surgical treatment of aortic valvular disease in rheumatoid arthritis. Medical Journal of Australia, 2, 384-387.

Iveson, J. M. I., Thadanis, M., and Wright, V. (1975) Aortic valvular incompetence and replacement in rheur matoid arthritis. Annals of the Rheumatic Diseases, 34 312-320.

Iveson, M. M. I., and Pomerance, A. C. (1977). Cardia involvement in rheumatoid disease. Clinics in Rheumatid Diseases, 3, 467-500.

Lebowitz, W. B. (1963). The heart in rheumatoid arthritisw (rheumatoid disease): a clinical and pathological study a 62 cases. Archives of Internal Medicine, 58, 102-123.

Roberts, W. C., Kehoe, J. A., Carpenter, D. F., and Golden? A. (1968). Cardiovascular lesions in rheumatoid arthritis 5 Archives of Internal Medicine, 122, 141-146.

Sokoloff, L. (1964). Cardiac involvement in rheumatoidD arthritis and allied disorders. Modern Concepts of Cardio vascular Disease, 33, 847-850.

Yates, D. B., and Scott, J. T. (1975). Cardiac valvular disease्ष in chronic inflammatory disorder of connective tissue尺 factors influencing survival. Annals of the Rheumatie Diseases, 34, 321-325. 